\title{
Air quality modelling of 2016 Madrid air pollution episode
}

\author{
$\underline{\text { R. San Joséa }}^{\text {, J.L. Pérez-Camaño }}{ }^{a}$, L. Pérez ${ }^{a}$ and R. M. Gonzalez-Barras ${ }^{b}$ \\ ${ }^{a}$ Environmental Software and Modelling Group, Computer Science School, Technical University of Madrid \\ (UPM), Madrid, Spain. ${ }^{b}$ Department of Physics and Meteorology, Faculty of Physics, Complutense \\ University of Madrid (UCM), Ciudad Universitaria, 28040 Madrid, Spain. \\ Email: roberto@fi.upm.es
}

\begin{abstract}
Urban air quality is one of the major environmental issues for cities and traffic emissions are one of the major sources of air pollution in urban areas; in the case of Madrid, $90 \%$ of emissions are produced by vehicles. Urban air quality presents a very important challenge due to spatial variability with high concentration gradients. In these cases, it is recommended to use computational fluid dynamics (CFD) models that explicitly resolve buildings and streets at high resolution. The aim of this work is to perform a simulation of a $\mathrm{NO}_{2}$ episode during December, 2016 in Madrid (Spain) city. The episode occurred from December 26 to 30, 2016, where $\mathrm{NO}_{2}$ hourly concentrations reached more than $250 \mu \mathrm{g} / \mathrm{m}^{3}$ at several monitoring stations. In December 2016, the levels of $\mathrm{NO}_{2}$ in Madrid were so high that authorities restricted access to the city centre for half of the cars based on whether the number plate was even or odd. The objective is to show how a multi-scale modeling tool from a mesoscale level to a micro-scale level can simulate the $\mathrm{NO}_{2}$ peaks measured by stations.
\end{abstract}

A multi-scale modelling system using the WRF/Chem (NCAR, US) mesoscale model and applying a downscaling approach from regional to city-scale (1 $\mathrm{km}$ spatial resolution) as well as a CFD-RANS (MICROSYS) model (5 m spatial resolution) has been applied and evaluated. In case of the MICROSYS, has no chemical reactions implemented so to convert $\mathrm{NO}$ into $\mathrm{NO}_{2}$ concentrations, a basic chemical scheme was developed in the CFD model. Traffic emissions are produced with the same horizontal resolution using the emission factors from EMEP-CORINAIR Tier 3 methodology (UNECE Air Convention). Traffic activity is one of the main input data for estimating road traffic emissions. The number of vehicle entries, vehicle mileage and speeds are needed for a detailed emission map. The traffic flows and vehicle speeds were simulated with the microscale SUMO model (DLR, Germany) using real traffic counters to calibrate the traffic demand. The simulations cover a period of 2 (spin up) +7 days. The CFD simulation reproduces the interactions between air flow and buildings with a very detail emission sources (traffic).

We show a substantial improvement in the model results when comparing with the CFD model results with the mesoscale model results. The results show also a much better simulations of the daily $\mathrm{NO}_{2}$ peaks. The CFD 5m simulation take into account the buildings and the complexity of urban environment to capture the complexity of local effects and reproduce the important local effects. The CFD model used has certain limitations such as using it in stationary mode and using a RANS approximation; the stationary state only provides an instantaneous distribution of pollutants. Of course with a higher computational capacity these limitations could be solved for example by using an LES (Large Eddy Simulation) approach. The coupled WRF/Chem-CFD modelling system is a reliable method to understand the complicated flow and pollutants dispersion within urban areas. The modelling system can be used as a tool to evaluate different emission reduction strategies at street level.

The integrated modelling system is suitable for testing and evaluating traffic-related emission mitigation strategies on a scale of metres and obtaining information on their effectiveness without actually having to implement it. One of the uses of the proposed modelling system is the possibility of carrying out various simulations changing traffic conditions and even changing the urban morphology (for example putting natural or artificial barriers for pollution) to obtain the impacts on the concentrations of this type of measures.

Keywords: Air quality, simulation, mesoscale, microscale, traffic emissions 
San José et al., Air quality modelling of 2016 Madrid air pollution episode.

\section{INTRODUCTION}

Urban air quality is one of the major environmental issues in cities. Traffic emissions are one of the major sources of air pollution in urban areas (Bernard et al., 2001), for example in the case of Madrid $90 \%$ of the emissions are coming from road transport. The high levels of pollutants such as $\mathrm{NO}_{2}, \mathrm{O}_{3}$ and particles found in cities can cause human health problems (mortality and morbidity), such as cardiovascular and respiratory problems (Kim et al., 2014). Local authorities need air quality simulation tools to reproduce the concentrations of pollutants in the most accurate way possible, to be able to evaluate interventions to reduce pollution before their application, which will allow to select the most effective measures (Halonen et al., 2016). Urban air quality presents a very important challenge due to the spatial variability with high concentration gradients. The large spatial variability of air pollution in an urban area is associated with the distribution of traffic emissions, (Wu et al., 2015) but also urban built environment (complex obstructions as buildings, canyon streets, etc.). The presence of different types of buildings (heights, orientation, etc.) in a city generates complex flow patterns and, consequently, heterogeneous pollutants dispersion in the streets of the city (Ghassoun et al., 2015). Pollutants emitted by vehicles are released very close to the surface on city streets. Once emitted, a complex dispersion of these pollutants is produced, affected by perturbations that buildings induce in the general flow of atmospheric circulation (Choi et al., 2016).With mesoscale models (up to $1 \mathrm{~km}$ spatial resolution) it is likely that it will not be feasible to capture local phenomena due to the low resolution of the emissions model and the insufficient representation of the urban surface. Mesoscale chemical transport models consider the instantaneous mixing of emission sources within each of the grid cells which does not allow modelling the spatial variability of urban air quality (Liu et al., 2011). In these cases, it is recommended to use computational fluid dynamics (CFD) models that explicitly resolve buildings and streets at high spatial and temporal resolution. (Wang et al., 2013). High resolution CFD models allow a more detailed description of the local and short-term dynamics of the urban atmosphere (Kwak et al., 2015). CFD models can be coupled with mesoscale models to consider local and mesoscale effects appropriately in a single, integrated modeling framework (Beevers et al., 2012).

Air quality models require accurate input emission data in order to make reliable predictions of ambient concentrations. CFD modeling requires a realistic emission rate of real-world street pollutants. Very detailed emission information is required if we want to identify "hot spots" of concentrated pollution in cities. Traffic emissions depend on the flow of vehicles, the speed of vehicles and the travel distance. All these data can be generated by a traffic model. An integrated model of micro-scale traffic and emissions is needed to study local air quality. In recent years, increased computing power has made it possible to make more practical use of microsimulation traffic models that predict the behaviour of each vehicle individually. The accuracy of the results will depend, at a large extent, on the reliability of traffic data (traffic volume and speed, its temporal and spatial variations, the composition of vehicle fleet, etc.) and the chosen emission factors for each type of vehicle. To try to reduce the results uncertainty obtained by the previous methods, a traffic model can be used to estimate, with higher accuracy, the detailed city traffic information (number and type of car in every time step and location). This is the solution adopted in the present research. The paper presents how a very high spatial-temporal resolution simulation with a nested mesoscale and a CFD model can reproduce a high peak of $\mathrm{NO}_{2}$ concentration. This study uses an integrated model system for local air quality by linking a CFD model with a mesoscale meteorological and chemical transport model. The air quality models are fed by a detailed emissions model that includes a microscale traffic model. This coupling makes it possible to calculate the concentration of pollutants with a resolution of $5 \mathrm{~m}$.

\section{CASE STUDY}

The $\mathrm{NO}_{2}$ episode occurred from December 26 to 30, 2016, where $\mathrm{NO}_{2}$ hourly concentrations reached 200 $\mu \mathrm{g} / \mathrm{m} 3$ in several monitoring stations. The air quality monitoring stations, where the maximum hourly levels of $\mathrm{NO}_{2}$ were reached, were located at: E. Aguirre station, located to the east of the city; the C. Caminos station, located to the north of the city centre and F. Ladreda station located outside the city centre and in the south of the city. Then the three stations (East, North and South) cover an area that corresponds to most of the city of Madrid, so we can assume that in the whole city high concentrations of $\mathrm{NO}_{2}$ pollutants for those days were found. The figure 1 shows the temporal evolution of the $\mathrm{NO}_{2}$ concentrations on the three mentioned monitoring stations. E. Aguirre station measured $286 \mu \mathrm{g} / \mathrm{m}^{3}$ on December, 27, 2016 20:00 hours. The $\mathrm{NO}_{2}$ measured concentrations show very weak morning peaks and highest concentrations recorded in the evening or at night. This behaviour is parallel to the city traffic flow.

The objective is to show how a multi-scale modeling tool from a mesoscale level to a micro-scale level can simulate the $\mathrm{NO}_{2}$ peaks measured by stations, particularly which of December 27 at E. Aguirre station. The simulation is performed for the period from 23 December 2016 to 31 December 2016, leaving the first two 
days as spin-up period. Mesoscale simulation uses three nested domains with 25, 5, and $1 \mathrm{~km}$ horizontal grid cell sizes. The mother domain covers the whole of Spain and the most inner and final one covers all of Madrid city area, with a $1 \mathrm{~km} \times 1 \mathrm{~km}$ spatial resolution. There are 33 vertical levels from surface to $50 \mathrm{mb}$, with finer resolution near the surface in all domains. With this domain configuration, we take into account both the large-scale transport of pollution at national and regional level, as well as the dispersion of pollution at urban scale. CFD simulation is performed for the same period. The domain size is $1000 \mathrm{~m}$ in the $\mathrm{x}-$ and $\mathrm{y}-$ directions and $250 \mathrm{~m}$ in the $\mathrm{z}$ direction surrounding the E. Aguirre monitoring station (the station with the highest $\mathrm{NO}_{2}$ concentrations). The grid size is $5 \mathrm{~m}$ in all directions.

\section{AIR QUALITY MODELLING SYSTEM}

The mesoscale simulation is run with using the Weather Research and Forecasting and Chem model with version 3.8.1 (WRF-Chem) (Grell et al., 2005) to study the $\mathrm{NO}_{2}$ episode in Madrid. The WRF/Chem model was configured as in phase 2 of the International Air Quality Model Assessment Initiative (AQMEII) (San José et al., 2015). The CFD model used in this study is MICROSYS (José R.S et al. 2008). MICROSYS solves the Reynolds-averaged Navier-Stokes equations (RANS) using k- $\varepsilon$ turbulence closure scheme (KIM, 2004). CFD is couple with the WRF/Chem mesoscale model. This is a one-way coupling. The components of wind, air temperature, turbulent kinetic energy and the concentration of various pollutants obtained from the WRF/Chem model are used as the initial and/or boundary conditions in the CFD every $15 \mathrm{~min}$. In case of the MICROSYS, with has no chemical reactions implementation. To convert NO concentrations into $\mathrm{NO}_{2}$ concentrations, a basic chemical scheme was developed in the CFD model (Jensen et al., 2001). For cold seasons (winter), this approach can be enough because the impact of photochemistry is less important than in warm periods. $\mathrm{NO}_{2}$ concentrations can be calculated using a steady state equation 1 .

$$
\left[\mathrm{NO}_{2}\right]=\frac{J}{K}[\mathrm{NO}]\left[\mathrm{O}_{3}\right]
$$

$\mathrm{K}$ is the reaction rate and $\mathrm{J}$ is the photolysis rate coefficient coming from the WRF/Chem urban simulation $1 \mathrm{~km}$. $\mathrm{K}$ is temperature dependent (Pu and Yang, 2014) and it is calculated by the equation 2 .

$$
K=3.23 e^{\frac{-1430}{T}}
$$

One of the key inputs for the air quality simulations is the emission data. In this case, Regional and urban non-transport-related anthropogenic emissions are taken from the TNO-MACC-II inventory (Kuenen et al., 2014). This inventory provides annual emissions data for Europe with a spatial resolution of $7 \mathrm{~km}$. These data have been processed by the EMIMO emission model (San José et al., 2008), to adapt them to the air quality model grids, according to the available data on population, road density and land use. The temporal disaggregation is based on monthly, daily and hourly profiles of Spain. Finally, the speciation of NMVOCs is carried out following the factors defined on Tuccella et al. 2012.

Traffic activity is one of the main input data for estimating road traffic emissions. The number of vehicle entries, vehicle mileage and speeds are needed for a detailed emission map. In out modelling system the traffic flow data were obtained using the SUMO traffic model (Krajzewicz et al., 2012). SUMO (Simulation of Urban Mobility) is an open source tool, space-continuous and time-discrete (1s.) traffic flow simulation platform. SUMO allows you to use traffic detector data to generate traffic demand. First, random traffic is generated for the Madrid network and then the road detectors have been used as calibrators, which have been used to adapt traffic demand to a certain set of strategies. Traffic conditions are extracted from the more than 3000 road detectors located in Madrid's streets and highways and 2/3 of them have been used to calibrate traffic simulations. The composition of the vehicles fleet was collected from vehicle registration data sets in Madrid for December 2016. In addition to the vehicle and fuel type, classification also takes into account the vehicle's engine type, vehicle technology (age of vehicles). More than 600 vehicle categories have been considered in the emissions model. The emission factors for urban road traffic have been calculated using the emissions factor the Tier 3 methodology described in the EMEP/EEA 2016 Atmospheric Pollutant Emissions Inventory Guide by using the December 2016 update (Passenger cars, light commercial trucks, heavy duty vehicles including buses and motorcycles). Vehicles are classified into different categories according to fuel type, vehicle weight, and vehicle age and engine capacity. For each category, specific emission factors are defined, which are dependent on the speed of the vehicles. 
San José et al., Air quality modelling of 2016 Madrid air pollution episode.

\section{RESULTS}

\subsection{Traffic simulation}

The simulated results are compared with traffic flow data obtained at $1 / 3$ of the traffic counters stations. Figure 1 shows hourly intensity (vehicles/hora) averaged over three traffic counters located around the E. Aguirre air quality station (the one that recorded the highest $\mathrm{NO}_{2}$ concentration value during the episode).

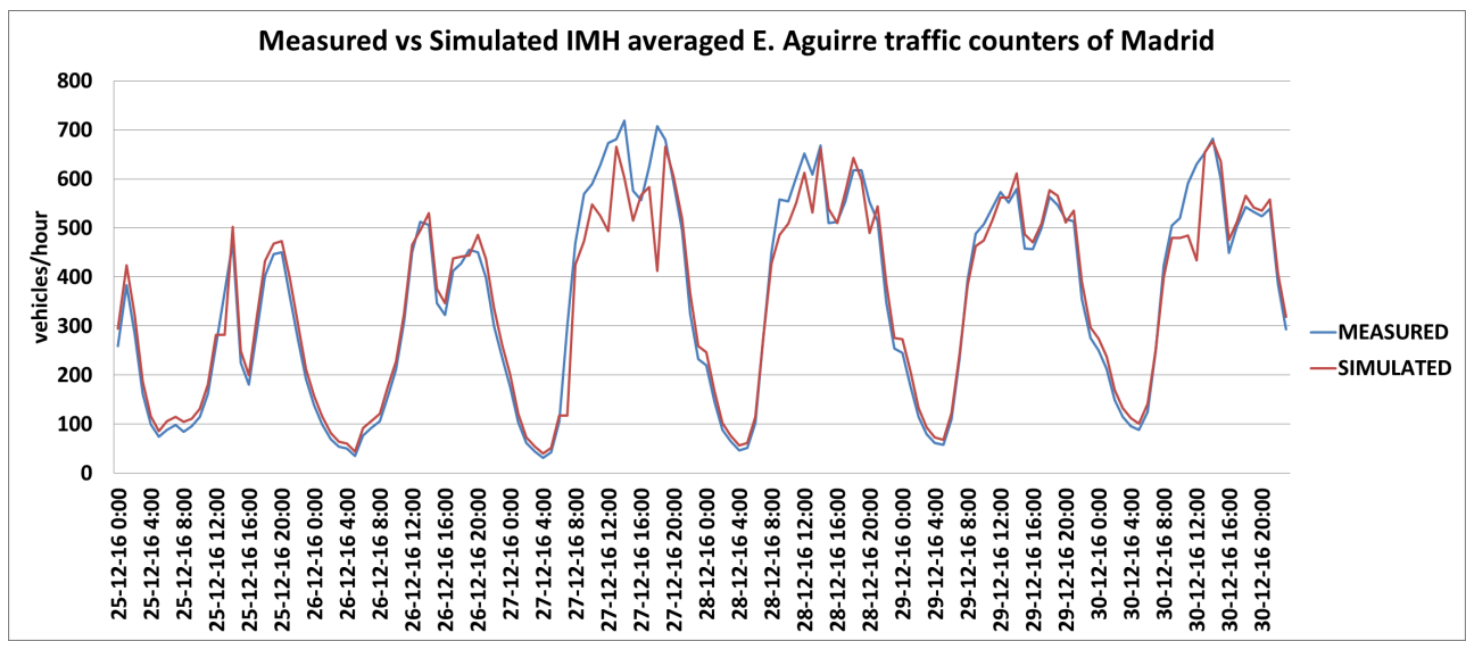

Figure 1. Hourly traffic intensity (vehicles/hour) measured and simulated from 25 December to 30 December, 2016 around E.Aguirre air quality station.

It can be observed that it is an area of high traffic density, with peaks of 700 vehicles/hour. It repeats the structure of 2 peaks, one in the morning and one in the afternoon. It is important to note that the 24th, 25th and 26th were bank holidays In these three traffic counters the SUMO model continues to perform very well, with a correlation coefficient $\mathrm{R}^{2}$ of 0.95 . Even in this area the maximum values of each day are clearly reached. The good quality of these data is key to generate emissions with a high spatial resolution ( 5 meters) of this area. The simulated traffic flow well reproduces the observations. The simulations show good agreement with the observed traffic flow. We can conclude that the SUMO traffic simulation represents the vehicles behaviour after being calibrated using $2 / 3$ of the traffic counters measurements.

\subsection{Mesoscale simulation}

Madrid air quality stations were used to evaluate the modelling system outputs for near-surface $\mathrm{NO}_{2}$. For evaluation purposes, we have compared the hourly model outputs for mesoscale simulation with the hourly observations. Figure 2 shows the performance of the WRF/Chem model vs Station AVG. Station AVG means the average of the values where the 24 stations are located around the city. The $\mathrm{NO}_{2}$ concentration ranges widely from $20 \mu \mathrm{g} / \mathrm{m}^{3}$ at a certain time, the daily maxima of the simulated and measured average $\mathrm{NO}_{2}$ concentrations are $160 \mu \mathrm{g} / \mathrm{m}^{3}$, at 19:00. The peak $\mathrm{NO}_{2}$ concentration is underestimated for the WRF/Chem simulation because $1 \mathrm{~km}$ is a coarse resolution for an urban simulation. In the hours of maximum measured concentrations, WRF/Chem $1 \mathrm{~km}$ is not able to reach these peaks because $\mathrm{NO}_{2}$ has a very strong spatial gradient over urban environments and resolution of $1 \mathrm{~km}$ is not enough We can observe that there is an overestimation of the simulated $\mathrm{NO}_{2}$ concentrations in the hours when the stations register the minimum values (night time 23:00 - 05:00 approx.).

Although the WRF/Chem model with $1 \mathrm{~km}$ resolution cannot detect $\mathrm{NO}_{2}$ peaks, in this period we found an overestimation of $19 \%$ of the model. Although the model does not optimally adjust to the maximum and minimum values, it does reproduce the hourly cycle of $\mathrm{NO}_{2}$ concentrations very well and a correlation coefficient is obtained between the measured and simulated data of 0.78 . This is very important because the results of the WRF/Chem $1 \mathrm{~km}$ model are used as initial and boundary values for the CFD 5m simulation. As it is an urban area of the 24 monitoring stations, 21 of them are classified as urban and/or traffic stations. In other words, the values they measure are highly affected by traffic emissions and obstacles such as buildings. This is the reason why the WRF/Chem $1 \mathrm{~km}$ model cannot model the large gradients that occur in $\mathrm{NO}_{2}$ concentrations and that it is necessary to take a further step in the simulation chain with a CFD model fed by maximum resolution traffic emissions. 


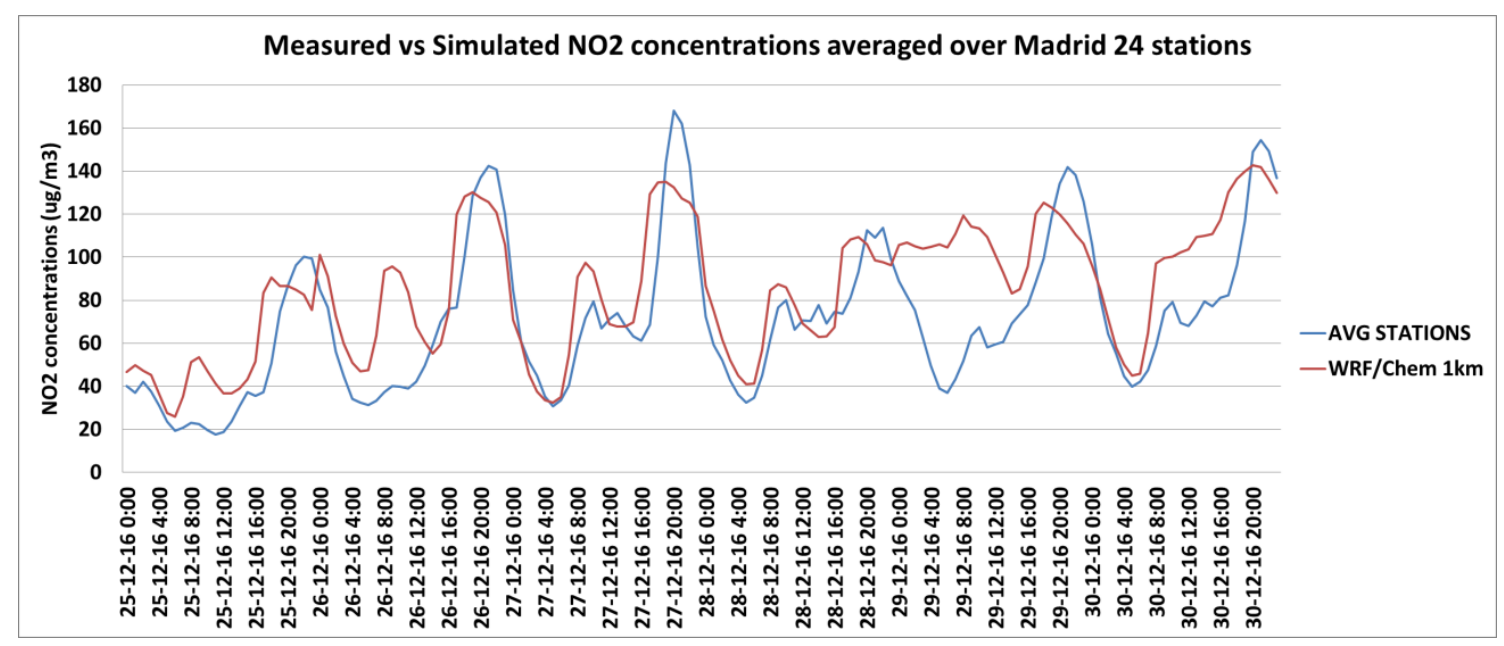

Figure 2. Time series of the simulated (red) and measured (blue) near-surface $\mathrm{NO}_{2}$ concentrations averaged over 24 air quality monitoring stations in the innermost WRF/Chem $(1 \mathrm{~km})$ model domain on 25,31

December, 2016

\subsection{Microscale simulation}

Now, the simulated $\mathrm{NO}_{2}$ concentrations by the integrated urban air quality modeling system (WRF/Chem $1 \mathrm{~km}$ and CFD 5m) are evaluated against the measured values at E. Aguirre air quality monitoring station on December 2016 peak $\mathrm{NO}_{2}$ episode. Results of the evaluation are shown in the Figure 3.

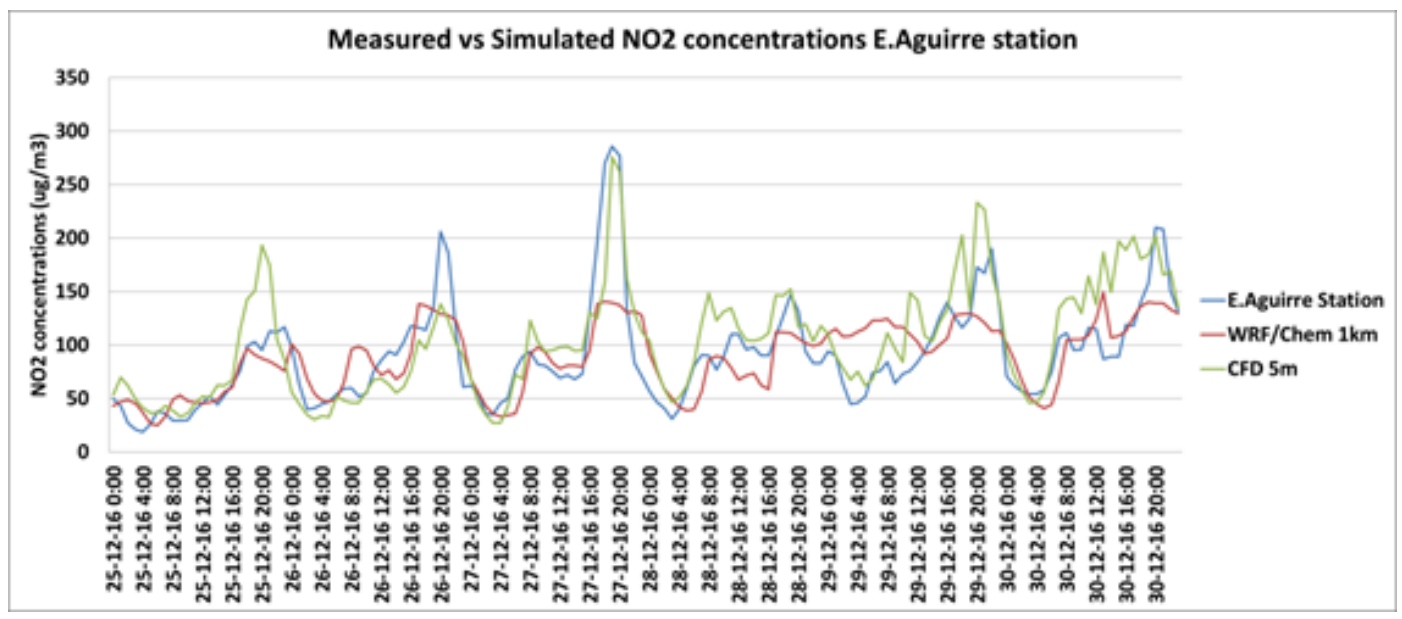

Figure 3. Time series of the near-surface $\mathrm{NO}_{2}$ concentrations for the E. Aguirre monitoring station (blue), WRF/Chem $1 \mathrm{~km}$ (red) and CFD 5m simulation (green) on 25,31 December, 2016.

As shown in Figures 2 and 3 the highest levels of $\mathrm{NO}_{2}$ occurred during peak traffic hours close to the 8 PM. E. Aguirre is a traffic station and there is a main street very close to it (next figure shows the position of the station). As expected, the $\mathrm{NO}_{2}$ concentration measured is better reproduced in the CFD 5m simulation than in the WRF/Chem $1 \mathrm{~km}$ simulation. The CFD $5 \mathrm{~m}$ simulation is capable of reproducing the $280 \mu \mathrm{g} / \mathrm{m}^{3}$ peak measured by the station on 27 December, 2016 19:00. But the CFD 5m simulation does not only improve the simulation of the daily maxima, but in general its performance is much better, for example the correlation coefficient of the WRF/Chem $1 \mathrm{~km}$ simulation is 0.68 and that of the CFD $5 \mathrm{~m}$ simulation has increased to 0.8 . Although it should not be forgotten that the CFD simulation is not independent, but uses data from the WRF/Chem $1 \mathrm{~km}$, hence the importance that it is also a good simulation with its limitations by spatial resolution. 
When comparing the values of the stations with the results of a modeling using grid structures, it must be taken into account that the model is always calculating the average value of the whole cell, in this case the results of the $\mathrm{WRF} / \mathrm{Chem} 1 \mathrm{~km}$ simulation reflect the average concentration of an area of $1 \mathrm{~km}$ per $1 \mathrm{~km}$. When we look at an urban area in detail we can see a high variability of concentrations at different points, hence the need to increase the spatial resolution and incorporate a tool to model all the structures of the area of $1 \mathrm{~km}$ by $1 \mathrm{~km}$ such as buildings and streets. The great variability of $\mathrm{NO}_{2}$ concentrations within a $1 \mathrm{~km}^{2}$ zone can be seen in Figure 4. High $\mathrm{NO}_{2}$ (over $250 \mu \mathrm{g} / \mathrm{m}^{3}$ ) levels are observed at the main street (Alcala Street) of the area, significantly lower levels $\left(30 \mu \mathrm{g} / \mathrm{m}^{3}\right)$ are observed inside the purple area which is an important park and garden inside of the city. There are also high concentrations in other streets in the area of $1 \mathrm{~km}$ by 1 $\mathrm{km}$, where traffic levels are much lower than those supported by the main street. In the study area, narrow streets with reduced ventilation can be found, where high

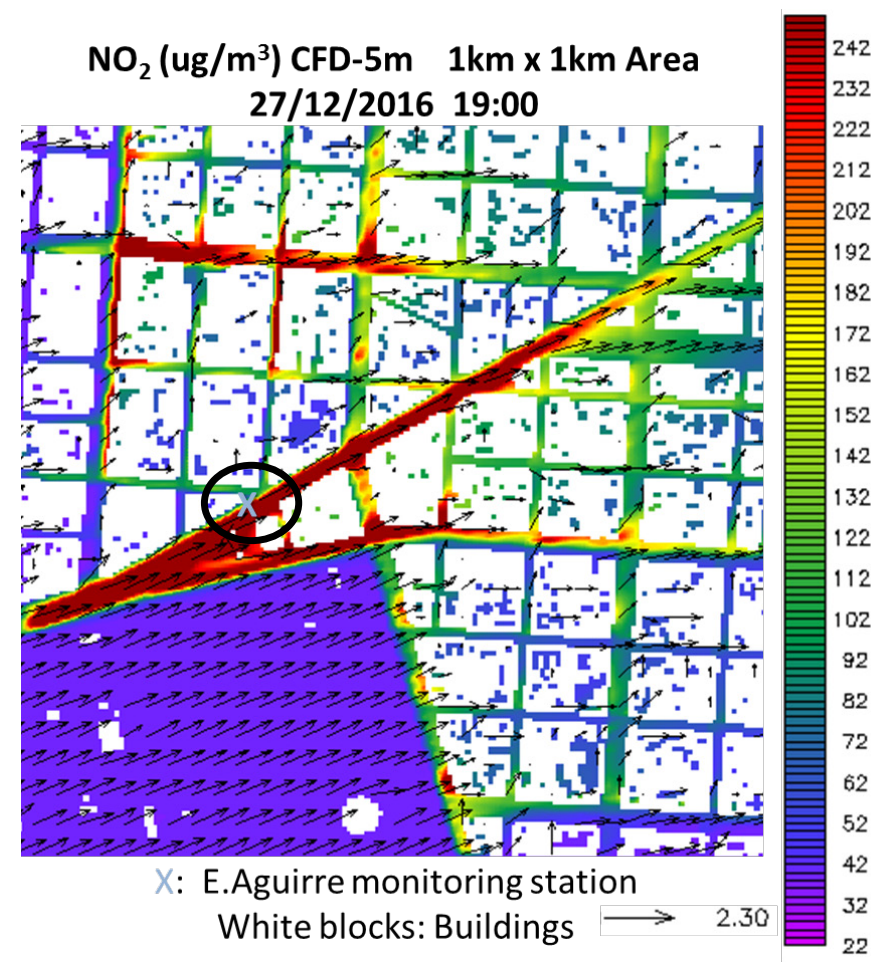

Figure 4. High resolution map of NO hourly concentration at 27/12/2017 19:00 produced by the CFD $5 \mathrm{~m}$ simulation over $1 \mathrm{~km}$ by $1 \mathrm{~km}$ area of Madrid. values of pollution from traffic are reached from the emissions of the main streets. There are several highly polluted places where the limit values established by the European Directive $\left(200 \mu \mathrm{g} / \mathrm{m}^{3}\right)$ are exceeded.

\section{CONCLUSIONS}

The $\mathrm{NO}_{2}$ concentrations in the mesoscale simulation (WRF/Chem 1km) and microscale (CFD 5m) simulation were evaluated with measured data of the Madrid air quality monitoring station, showing the better agreements with CFD $5 \mathrm{~m}$ model because the $\mathrm{NO}_{2}$ dispersion exhibits a high spatial variabilities associated with the local influences of traffic emission and buildings. The evaluation of the performance of the WRF/Chem $1 \mathrm{~km}$ was satisfactory, with good values in the correlation coefficients, although at some local points the system has not been able to reach the maximum (hourly average values) peaks of $\mathrm{NO}_{2}$ concentrations measured by monitoring stations. Resolution of $1 \mathrm{~km}$ has not been enough to capture some very local concentration peaks. The CFD $5 \mathrm{~m}$ simulation reproduces pollutant dispersion in the presence of proper inflow boundary conditions supplied by the WRF/Chem $1 \mathrm{~km}$ simulation and real building morphology. The CFD $5 \mathrm{~m}$ simulates strong spatial $\mathrm{NO}_{2}$ gradients. The results show good agreement, thus proving that the CFD method is highly competent in handling complex urban air pollution issues.

The evaluation of the CFD simulation has only been performed for one area of $1 \mathrm{~km}$ by $1 \mathrm{~km}$. Of course it will be necessary to extend the study to new areas of $1 \mathrm{~km}$ by $1 \mathrm{~km}$ where there are air quality stations to obtain more robust conclusions, which requires a very intensive computations exercise which will be developed in the next works. The results obtained allow us to confirm that the modeling tool presented is capable of satisfactorily reproducing the distribution of the concentration of pollutants along the streets of an area of the city with high traffic volumes. It becomes a key tool to analyze the measures to be taken to improve the air quality of an area or even the entire city.

\section{ACKNOWLEDGMENTS}

The UPM authors thankfully acknowledge the computer resources, technical expertise and assistance provided by the Centro de Supercomputación y Visualización de Madrid (CESVIMA). 
San José et al., Air quality modelling of 2016 Madrid air pollution episode.

\section{REFERENCES}

Beevers, S., Kitwiroon, N., Williams, M. and Carslaw, D. (2012). One way coupling of CMAQ and a road source dispersion model for fine scale air pollution predictions. Atmospheric Environment, 59, pp.47-58.

Bernard, S., Samet, J., Grambsch, A., Ebi, K. and Romieu, I. (2001). The potential impacts of climate variability and change on air pollution-related health effects in the United States. Environmental Health Perspectives, 109(suppl 2), pp.199-209.

Choi, W., Ranasinghe, D., Bunavage, K., DeShazo, J., Wu, L., Seguel, R., Winer, A. and Paulson, S. (2016). The effects of the built environment, traffic patterns, and micrometeorology on street level ultrafine particle concentrations at a block scale: Results from multiple urban sites. Science of The Total Environment, 553, pp.474-485.

Ghassoun, Y., Ruths, M., Löwner, M. and Weber, S. (2015). Intra-urban variation of ultrafine particles as evaluated by process related land use and pollutant driven regression modelling. Science of The Total Environment, 536, pp.150-160.

Grell, G., Peckham, S., Schmitz, R., McKeen, S., Frost, G., Skamarock, W. and Eder, B. (2005). Fully coupled "online" chemistry within the WRF model. Atmospheric Environment, 39(37), pp.6957-6975.

Halonen, J., Blangiardo, M., Toledano, M., Fecht, D., Gulliver, J., Anderson, H., Beevers, S., Dajnak, D., Kelly, F. and Tonne, C. (2016). Long-term exposure to traffic pollution and hospital admissions in London. Environmental Pollution, 208, pp.48-57.

Jensen, S., Berkowicz, R., Sten Hansen, H. and Hertel, O. (2001). A Danish decision-support GIS tool for management of urban air quality and human exposures. Transportation Research Part D: Transport and Environment, 6(4), pp.229-241.

José R.S., Pérez J.L., Morant J.L., González R.M. (2008) CFD and Mesoscale Air Quality Modelling Integration: Web Application for Las Palmas (Canary Islands, Spain). In: Borrego C., Miranda A.I. (eds) Air Pollution Modeling and Its Application XIX. NATO Science for Peace and Security Series Series C: Environmental Security. Springer, Dordrecht

Kim, B., Lee, S., Kwon, J., Jung, Y., Lee, E., Yang, S., Kim, H., Seo, J., Kim, H., Kim, H., Leem, J., Kwon, H. and Hong, S. (2014). Traffic-related air pollution is associated with airway hyperresponsiveness. Journal of Allergy and Clinical Immunology, 133(6), pp.1763-1765.e2.

KIM, J. (2004). A numerical study of the effects of ambient wind direction on flow and dispersion in urban street canyons using the RNG k?? turbulence model. Atmospheric Environment, 38(19), pp.3039-3048.

Krajzewicz, D., J. Erdmann, M. Behrisch, and L. Bieker (2012) Recent Development and Applications of SUMO - Simulation of Urban Mobility. International Journal On Advances in Systems and Measurements, 5 (3\&4), pp. 128-138.

Kwak, K., Baik, J., Ryu, Y. and Lee, S. (2015). Urban air quality simulation in a high-rise building area using a CFD model coupled with mesoscale meteorological and chemistry-transport models. Atmospheric Environment, 100, pp.167-177.

Kuenen, J., Visschedijk, A., Jozwicka, M. and Denier van der Gon, H. (2014). TNO-MACC_II emission inventory; a multi-year (2003\&amp;ndash;2009) consistent high-resolution European emission inventory for air quality modelling. Atmospheric Chemistry and Physics, 14(20), pp.10963-10976.

Liu, Y., Cui, G., Wang, Z. and Zhang, Z. (2011). Large eddy simulation of wind field and pollutant dispersion in downtown Macao. Atmospheric Environment, 45(17), pp.2849-2859.

$\mathrm{Pu}, \mathrm{Y}$. and Yang, C. (2014). Estimating urban roadside emissions with an atmospheric dispersion model based on in-field measurements. Environmental Pollution, 192, pp.300-307.

San José, R., Pérez, J., Morant, J. and González, R. (2008). European operational air quality forecasting system by using MM5-CMAQ-EMIMO tool. Simulation Modelling Practice and Theory, 16(10), pp.1534-1540.

Tuccella, P., Curci, G., Visconti, G., Bessagnet, B., Menut, L. and Park, R. (2012). Modeling of gas and aerosol with WRF/Chem over Europe: Evaluation and sensitivity study. Journal of Geophysical Research: Atmospheres, 117(D3), p.n/a-n/a.

Wang, Y., Nguyen, M., Steffens, J., Tong, Z., Wang, Y., Hopke, P. and Zhang, K. (2013). Modeling multiscale aerosol dynamics and micro-environmental air quality near a large highway intersection using the CTAG model. Science of The Total Environment, 443, pp.375-386.

Wu, H., Reis, S., Lin, C., Beverland, I. and Heal, M. (2015). Identifying drivers for the intra-urban spatial variability of airborne particulate matter components and their interrelationships. Atmospheric Environment, 112, pp.306-316. 